\title{
Dependence of Molecular Weight and Concentration of Reactive Side Chains on the Mechanical Properties of Cured Brominated Poly(4-methacryloyloxystyrene) Derivatives
}

\author{
Masao Suzuki, Akira Nagai, Junichi Katagiri, and Akio Takahashi \\ Hitachi Research Laboratory, Hitachi Ltd., \\ 7-1-1, Omika-cho, Hitachi-shi, Ibaraki 319-12, Japan
}

(Received July 21, 1994)

\begin{abstract}
Brominated poly(4-methacryloyloxystyrene) derivatives with different molecular weights and different concentrations of reactive side chains were synthesized. They were heated with radical initiator to be highly crosslinked products. Free volume of cured products increased with molecular weight of the starting materials. The thermal expansion coefficient and peak temperature of $\beta$-dispersion became lower with increasing free volume of the cured products. These results may be attributed to the dependence of molecular weight on the balance between intermolecular and intramolecular reactions. Many intramolecular reactions may lead to loop formation, when the molecular weight of the starting polymer is high.

KEY WORDS Brominated Poly(4-methacryloyloxystyrene)/Free Volume / Mechanical Property / Viscoelastic Property /
\end{abstract}

Three-dimensional network polymers are generally built from monomers with polyfunctional reactive groups, and the relationships between the structures of cured products and their physical properties have been studied for many years. Polymers having reactive side groups also build three-dimensional networks and have been studied for application as photo resists, insulators for electrical materials, ${ }^{1-3}$ etc. It is expected that the concentrations of reactive side groups and molecular weight of these polymers do not affect only reactivity but also structure, mechanical properties, and other physical properties of crosslinked products. Therefore, for technical uses, it is very important to study the relationship between the structure of starting material and structure of crosslinked product. Koseki et al. studied this relationship using photoresists. ${ }^{4-6}$ On the other hand, it is generally difficult to study the structure of crosslinked product because they are insoluble.

Earlier, we synthesized and characterized brominated poly(4-hydroxystyrene) derivatives having many kinds of pendant functional groups such as methacryloyl and acryloyl groups. ${ }^{7}$ Brominated poly(4-methacryloyloxystyrene) were used as a flame retarder for multi layered circuit boards. ${ }^{6}$ In this paper, we use brominated poly(4-methacryloyloxystyrene) derivatives with different concentration of reactive side groups and molecular weights, and study the relationship of the network microstructures and mechanical properties of the cured products.

\section{EXPERIMENTAL}

\section{Materials and Sample Preparation}

The chemical structures of synthesized polymers are shown in Figure 1. The polymers that have only a methacryloyl group as the side chain were called the M-series (M-1, M-2, M-3, M-4, and M-5). These have different molecular weights. The R-series (R-1, R-2, and R-3) consists of polymers that have methacryloyl 
and isobuthyloyl groups at the ratio $5: 5,3: 7$, and $1: 9$, respectively. Their molecular weights, bromine contents, and unsaturated group contents are summarized in Table I. All polymers were synthesized by reactions of brominated poly(4-hydroxystyrene) (HS) (Maruzen Petrochemical Co., Ltd.) with the corresponding acyl chlorides in dichloromethane and water mixture solvents as reported in our earlier paper. ${ }^{7}$ To synthesize brominated poly(methacryloyloxystyrene) with different molecular weights (M-series), we used HS with different molecular weights. Representative examples of synthetic procedure for $\mathrm{R}$-series polymers is as follows.

Brominated poly(sodium 4-vinylphenolate) and a mixture of isobutryl chloride and methacryloyl chloride, with molar ratios at 5:5, $7: 3$, and $9: 1$, were reacted in the phase transfer reaction with two liquid phases. The prod-

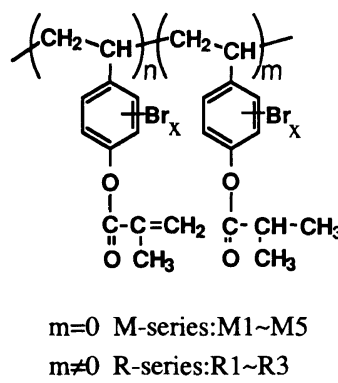

Figure 1. Chemical structure of brominated poly(4methacryloyloxystyrene) derivatives. ucts were insoluble in the water phase but soluble in organic solvents. They were purified by reprecipitation with acetone and methanol, three times, and dried in vacuo at room temperature for 20 hours. The yields were between 97 and $98 \%$. The synthesized products were identified by IR and ${ }^{1} \mathrm{H}$ NMR. The ratios of unreactive side groups to reactive side groups were measured by ${ }^{1} \mathrm{H}$ NMR. The intensity ratio of the $\mathrm{CH}_{2}$ to the proton atom of the aromatic ring gives a concentration of the reactive side group.

The obtained polymers were dissolved in acetone to make $50 \mathrm{wt} \%$ solutions. Two parts of hundred resins (phr) of 2,5-dimethyl-2,5di( $t$-buthylperoxy)hexine-3 (Nippon Oil and Fats Co., Ltd.) was added to each solution as a radical initiator. Acetone was removed and the polymers were dried. They were placed in a heated molding press with a $1 \mathrm{~mm}$ spacer and cured under a pressure of $40 \mathrm{kgf} \mathrm{cm}^{-2}$. The molding temperature was $170^{\circ} \mathrm{C}$ for $60 \mathrm{~min}$ utes, and raised to $250^{\circ} \mathrm{C}$ and held for 2 hours. Transparent samples of crosslinked products were obtained.

\section{IR Spectra}

IR spectra were obtained on a Hitachi 260 50 model spectrometer by the $\mathrm{KBr}$ method.

\section{${ }^{1} H N M R$}

NMR measurements were made using a

Table I. Synthesized polymers

\begin{tabular}{cccccc}
\hline & \multicolumn{2}{c}{ Distribution of molecular weight } & \multicolumn{2}{c}{$\begin{array}{c}\text { Concentration of } \\
\text { saturated group/\% }\end{array}$} & $\begin{array}{c}\text { Concentration of } \\
\text { bromine } / \%\end{array}$ \\
\cline { 2 - 5 } & $M_{n}$ & $M_{w}$ & $M_{w} / M_{n}$ & & 45.4 \\
M-1 & 3881 & 8298 & 2.14 & 0 & 46.6 \\
M-2 & 4025 & 11224 & 2.79 & 0 & 43.3 \\
M-3 & 4497 & 8948 & 1.99 & 0 & 46.4 \\
M-5 & 6939 & 16083 & 2.32 & 0 & 43.6 \\
R-1 & 7704 & 19536 & 2.54 & 0 & 44.9 \\
R-2 & 5666 & 15226 & 2.69 & 44.7 & 46.3 \\
R-3 & 3953 & 10585 & 2.78 & 66.7 & 47.2 \\
\hline
\end{tabular}


Hitachi R-250 spectrometer at $270 \mathrm{MHz}$.

Sample tube diameter was $5 \mathrm{~mm}$ and sample concentration $2 \mathrm{mg} \mathrm{ml}^{-1}$ of $\mathrm{CD}_{3} \mathrm{Cl}$. Chemical shifts were reported relative to TMS.

\section{Molecular Weights}

The molecular weights of the products were measured by Hitachi L-400 model gel permeation chromatography with tetrahydrofuran as the eluent. The flow rate was $1.75 \mathrm{ml} \mathrm{min}^{-1}$. Molecular weights were characterized using polystyrene standards.

\section{Density Measurements}

Density was evaluated using a bromoformtoluene mixture liquid of the same density at $25^{\circ} \mathrm{C}$. The density of the corresponding mixture was measured on an Anton Parr precision density meter (DMA-02C). Specific volume was calculated from this density.

\section{The Coefficient of Linear Thermal Expansion Measurements}

Thermal expansion behavior was measured from room temperature to $250^{\circ} \mathrm{C}$ at a heating rate of $2 \mathrm{~K} \mathrm{~min}^{-1}$ on a Shinku-Riko ThermoMechanical Analyzer (TM3000). The thermal expansion coefficient (TEC) was calculated from the above data between $60^{\circ} \mathrm{C}$ and $120^{\circ} \mathrm{C}$.

\section{Viscoelastic Measurements}

Dynamic mechanical properties were determined using an Iwamoto Seisakusho device (RPX-706) from -180 to $280^{\circ} \mathrm{C}$ at a heating rate of $2 \mathrm{~K} \mathrm{~min}^{-1}$, using forced longitudinal vibration at $10 \mathrm{~Hz}$. The samples were rectangular strips, $40 \times 4 \times 1 \mathrm{~mm}$.

\section{Flexural Measurements}

Flexural testing by the modified JIS-K6911 procedure was conducted on a Shimadzu Autograph (DDS-5000) at room temperature.

\section{RESULTS}

Characterization of the Synthesized Polymers

The synthesized polymers were characterized by IR, ${ }^{1} \mathrm{H}$ NMR, and elemental analysis. ${ }^{7}$ Figure 2 shows the spectra of HS and M-1. The latter is a typical spectrum of synthesized polymers. HS has several absorbance peaks due to hydroxy group; 1320 , and $1150 \mathrm{~cm}^{-1}$. But the IR spectrum of M-1 does not have any absorbance due to hydroxyl groups. And absorbance peaks resulting from introduction of alkenyl, carbonyl, and vinyl groups appear in the spectra at 1750,1130 , and $980 \mathrm{~cm}^{-1}$, respectively. In the $\mathrm{R}$-series, the ratios of unreactive side groups to reactive side groups could be measured from the data of ${ }^{1} \mathrm{H}$ NMR as shown in Figure 3. The $\mathrm{CH}_{2}$ moiety of the vinyl group in the side chain exhibits two separate peaks at 6.4 and $5.8 \mathrm{ppm}$. In Figure 3 , b represents the area attributed to proton atoms of the vinyl group and a the area of proton atoms of the aromatic ring. The concentration of the reactive side chain is determined from the ratio of $\mathbf{b}$ to $\mathbf{a}$. The molecular weights of obtained polymers are summarized in Table I. Polydispersity indexes, $M_{n} / M_{w}$, were from 1.99 to 2.80 .

\section{Physical Properties of the Cured Products}

Two phr of 2,5-dimethyl-2,5-di( $t$-buthylper-

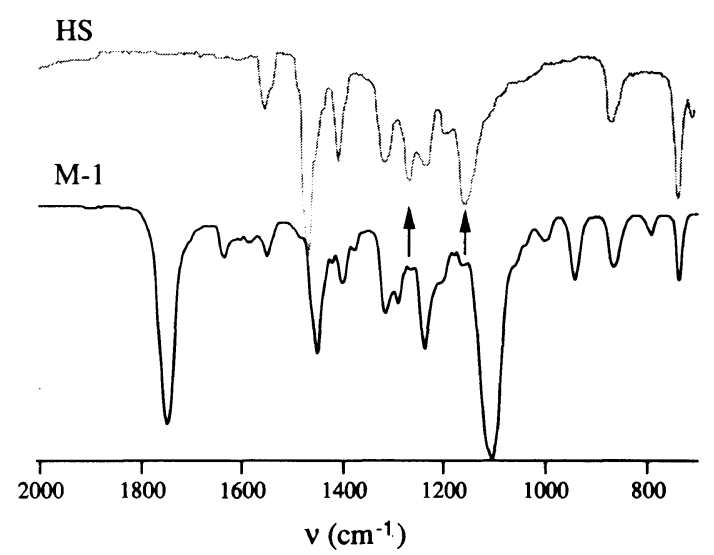

Figure 2. IR spectra of polymers. 
oxy)hexine-3 was added to the synthesized starting material as the initiator. The mixture was molded under pressure in the hot molding press. The obtained products were all brownish transparent plates. Table II summarizes the

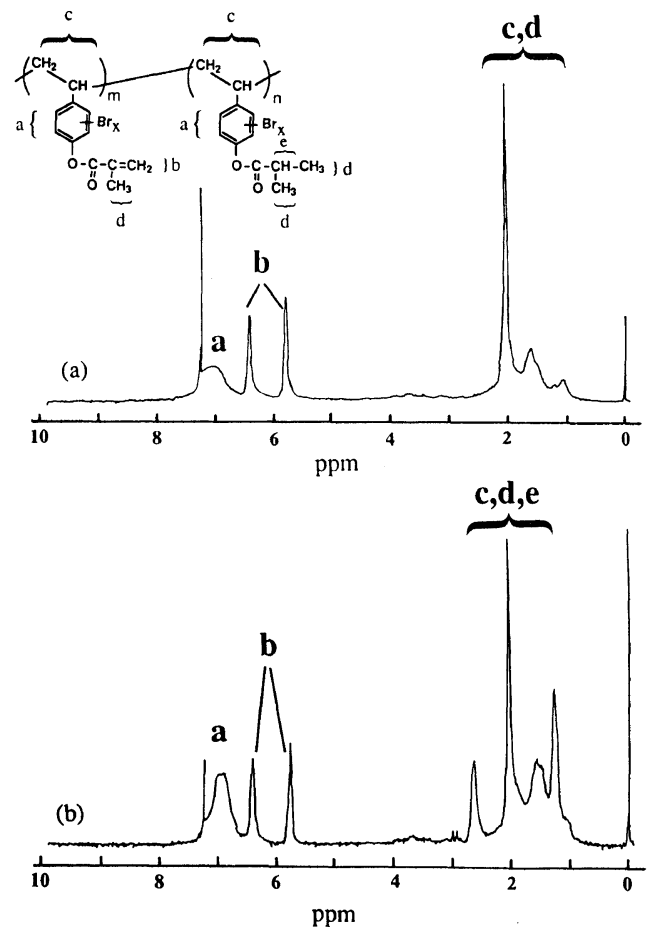

Figure 3. ${ }^{1} \mathrm{H}$ NMR spectra and chemical structures of brominated poly(4-methacryloyloxystyrene) derivatives. physical and mechanical properties of the products.

The samples were very brittle as shown by their low flexural strength and elongation. In addition, the flexural modulus became lower as the molecular weights of starting materials increased. In particular, M-5 that has the highest molecular weight in the $\mathbf{M}$-series could not be molded to a size large enough for the flexural test because of its brittleness. The cured product of $\mathrm{R}-1$, which has only $50 \%$ reactive groups and a molecular weight as much as that of M-3, has a low modulus and high elongation compared with those of the M-series. Its crosslinking density may be smaller than those of the M-series because the density of the reactive groups is lower. $\mathrm{R}-2$ and $\mathrm{R}-3$ that have more unreactive groups than $\mathrm{R}-1$ could not be made into plates. The cured product obtained from R-3 dissolved in organic solvents, indicating that it did not sufficiently form a three-dimensional network.

\section{Viscoelastic Property of the Cured Products}

Figure 4 shows viscoelastic data of $\mathrm{M}-1$ as a typical example of the $\mathrm{M}$-series. All the $\mathrm{M}$-series has a broad dispersion from 60 to $90^{\circ} \mathrm{C}$. And the distinct glass transition temperature did not appear in the data of the thermal expansion measurement until $280^{\circ} \mathrm{C}$.

Table II. Physical properties of cured products

\begin{tabular}{|c|c|c|c|c|c|c|}
\hline \multirow{4}{*}{ Sample } & \multirow{4}{*}{$\frac{\text { Density }}{\mathrm{g} \cdot \mathrm{cm}^{-3}}$} & \multirow{4}{*}{$\frac{\text { Specific volume }}{\mathrm{cm}^{3} \cdot \mathrm{g}^{-1}}$} & \multirow{4}{*}{$\frac{\mathrm{TEC}^{\mathrm{a}}}{10^{5} \mathrm{~K}^{-1}}$} & \multicolumn{3}{|c|}{ Flexural property } \\
\hline & & & & \multirow{3}{*}{$\frac{\text { Modulus }}{\text { GPa }}$} & \multirow{3}{*}{$\begin{array}{c}\text { Strength } \\
\mathrm{MPa}\end{array}$} & \multirow{3}{*}{$\frac{\text { Elongation }}{\%}$} \\
\hline & & & & & & \\
\hline & & & & & & \\
\hline M-1 & 1.88 & 0.53 & 6.25 & 1.63 & 29.0 & 1.82 \\
\hline M-2 & 1.75 & 0.57 & 5.65 & 1.85 & 32.3 & 1.73 \\
\hline M-3 & 1.61 & 0.62 & 4.95 & 1.90 & 23.3 & 1.07 \\
\hline M-4 & 1.68 & 0.59 & 5.42 & 2.04 & 28.1 & 1.41 \\
\hline M-5 & 1.48 & 0.68 & 5.58 & - & - & - \\
\hline R-1 & 1.74 & 0.58 & 4.80 & 0.807 & 26.3 & 3.55 \\
\hline R-2 & 1.94 & 0.52 & 5.70 & - & - & - \\
\hline
\end{tabular}

a Thermal expansion coefficient. 


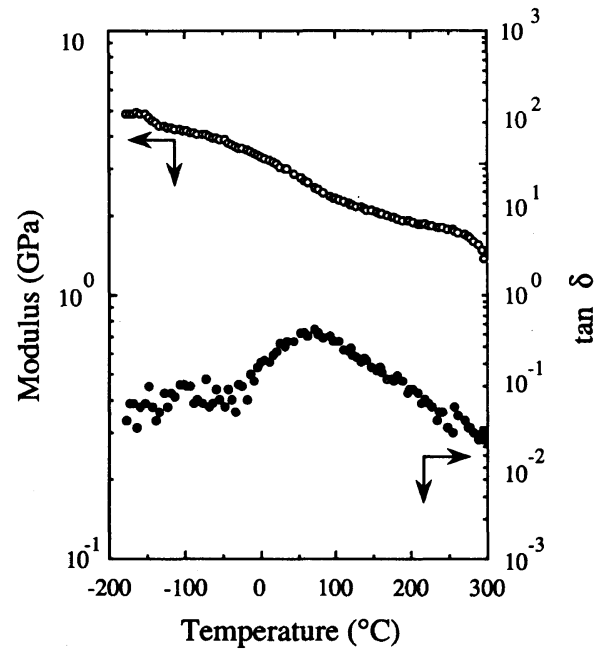

Figure 4. Viscoelastic data for cured M-1.

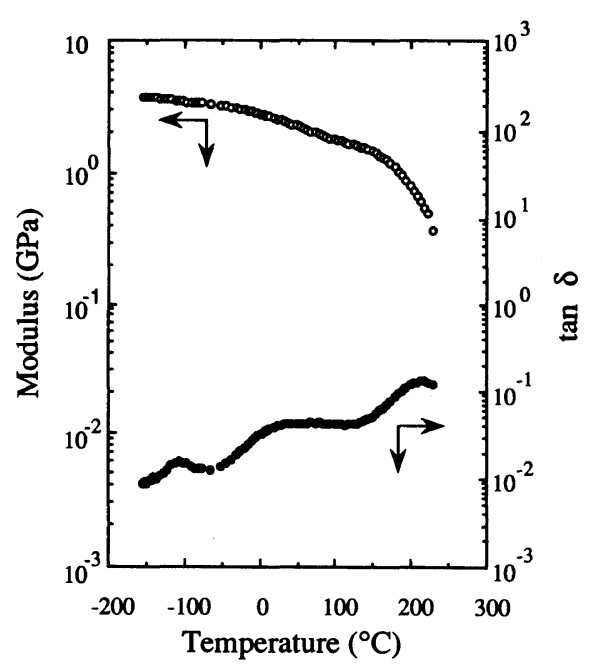

Figure 5. Viscoelastic data for cured R-1.

The cured R-1 has an $\alpha$-dispersion attributed to the glass transition at $210^{\circ} \mathrm{C}$ as shown in Figure 5. It has a lower glass transition temperature compared with the $\mathrm{M}$-series because R-1 has about only $50 \%$ reactive side chains; therefore, crosslinking density of cured one is lower and its main chain has more mobility compared with the M-series. Thus, the glass transition temperatures of cured $\mathbf{M}$-series may be over $280^{\circ} \mathrm{C}$, and we consider a broad dispersion in Figure 4 the $\beta$-dispersion attribut- ed to the local relaxation of the side groups or segments of the polymer.

\section{DISCUSSION}

\section{Relationship between Free Volume of Cured Products and Molecular Weights of Starting Materials}

Many physical properties of cured products are generally dependent on chemical structure, crosslinking density, ${ }^{5}$ and free volume. The M- and R-series samples have similar chemical structure, so their properties are governed by crosslinking density, free volume, or other network microstructures. The relationship between the crosslinking density and physical properties of the three-dimensional network polymer are very important. We can calculate crosslinking density by using the elastic modulus in the rubber region. However, the $\alpha$ dispersion of the $\mathbf{M}$-series could not be observed below testing temperature region as shown in Figure 5. It may be over $280^{\circ} \mathrm{C}$. Therefore, its crosslinking density could not be estimated by viscoelastic results. In the case of other M-series polymers, crosslinking densities could not be obtained.

The free volume provides a simple index of configurational structure and many physical properties of polymers should be related to free

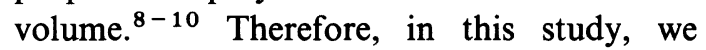
examined the relationship between the free volume and other physical properties of cured product. Generally, free volume, $V_{f}$, can be expressed as:

$$
V=V_{\mathrm{f}}+V_{0}
$$

where $V$ is the total specific volume and $V_{0}$ occupied volume. ${ }^{11}$ This relationship is shown in Figure 6. Since these M-series polymers have the same chemical structure, their $V_{0}$ can be considered almost equal. The situation is similar for the R-series. Therefore, $V$ should reflect the amount of free volume. So, it is important to study the relationship between $V$ and physical properties of cured products. 


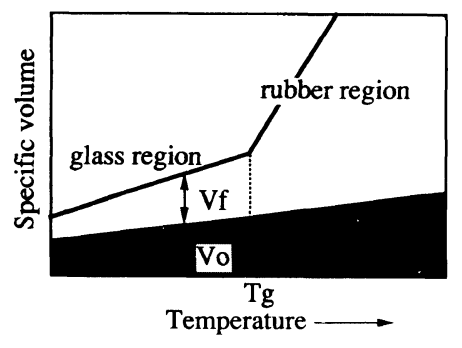

Figure 6. Specific volume of a polymer.

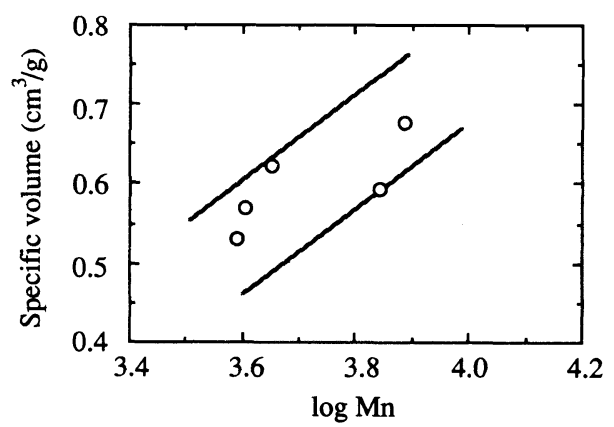

Figure 7. Relationship between specific volume of a cured product and molecular weight of the starting material (M-series).

Figure 7 shows the dependence of molecular weight of the starting material on the specific volume, $V$, of cured products. The specific volume increases with the molecular weight of starting material.

Relationship between Physical Properties and Free Volume of Cured Products

For epoxy resin systems, the specific volume is higher with increasing of crosslinking density. ${ }^{11}$ The reason for this result may be as follows. In the rubbery regions of cured resins, molecules move freely. When cooling down under the glass transition temperature, molecular motion is frozen. Crosslinks of cured resins restrict a specific volume in the glass region. Therefore, the more crosslinks, the more the free volume. The thermal expansion coefficient (TEC) of cured resin increases with crosslinking density, because the free volume is more. ${ }^{11}$ In our case, however, TEC of cured M-series decreased with increasing specific

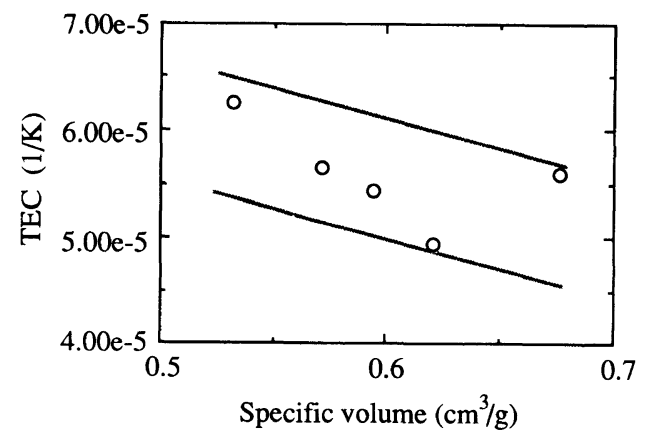

Figure 8. Dependence of specific volume on TEC of the cured M-series.

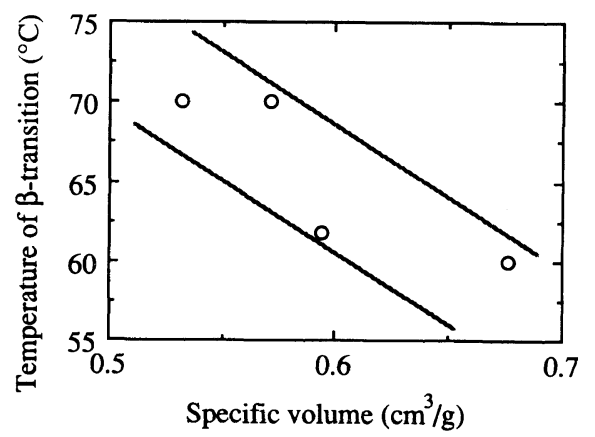

Figure 9. Relationship between specific volume and $\beta$ transition temperature (M-series).

volume as shown in Figure 8.

Free volume may govern the mobility of side groups or segments of the polymer. Figure 9 shows the relationship between specific volume and peak temperature of $\beta$-dispersion, $T_{\beta}$. The $\beta$-dispersion is attributed to the local relaxation of the side groups or segments of the polymer. In this case, as $V$ becomes larger, $T_{\beta}$ sifts lower. This suggests that the mobility of side groups or segments of polymer becomes higher on increasing the free volume of cured products.

\section{Estimation of the Structures of Cured Products}

To explain the results above, we propose the mechanism shown in Figure 10 in which intramolecular reaction occurs as a competitive reaction with the intermolecular reaction when the molecular weight of the starting polymer is high. That is, many intramolecular reactions 


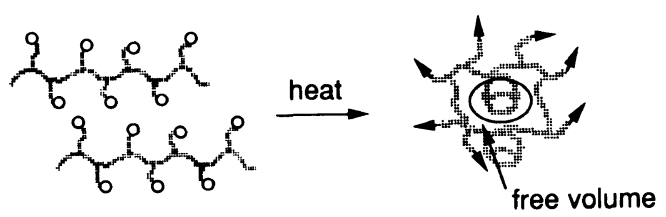

(a)

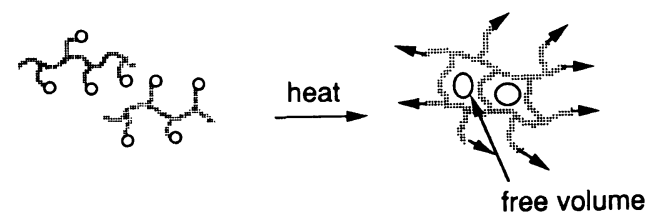

(b)
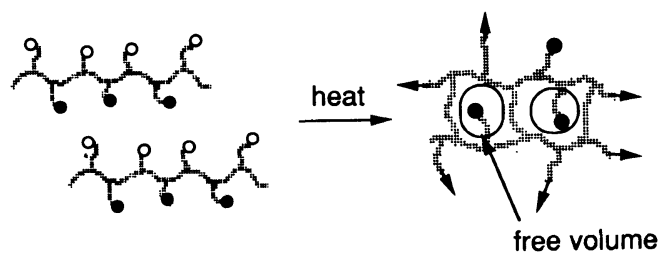

(c)

Figure 10. Relationship between starting material and structures of cured products. Molecular weight is (a) higher (b) lower, and (c) starting material has reactive $(O)$ and unreactive side groups $(\mathbf{O})$.

may lead to loop formation, which causes increased of the free volume of cured products because the loops may cause considerable steric hindrance when the molecular weight of the starting polymer is high. This difference in the network microstructure is also related to the mechanical properties of cured product. This steric hindrance may cause a relatively high modulus when cured products of $\mathbf{M}$-series have a higher free volume as shown in Table II.

Effective crosslinking density is reduced with increasing intramolecular reaction. Cured products have less elongation when molecular weights of starting materials increase.

\section{CONCLUSIONS}

Brominated poly(4-methacryloyloxystyrene) derivatives with different molecular weights and concentrations of reactive side chains were synthesized. The cured products could be obtained by the molding under pressure and all were brownish transparent plates. Because of the high crosslinking density, they were very brittle. There was no $\alpha$-dispersion attributed to glass transition except for the polymer with many unreactive side chains. The free volume of cured products increased with molecular weight of the starting material. TEC and peak temperature of $\beta$-dispersion of cured products decreased with increasing specific volume, possibly due to the mobility of side groups or segments of the polymer chain. These results may be attributed to the dependence of molecular weight on the balance between intermolecular and intramolecular reactions. A mechanism of the network microstructure of cured products is proposed.

\section{REFERENCES}

1. J. A. Schroeder, P. A. Madsen, and R. T. Foister, Polymer, 28, 929 (1987).

2. K. Hasegawa, M. Fukuda, S. Tonogai, and K. Ueda, Netukoukaseijusi, 10, 98 (1989).

3. J. Katagiri, A. Nagai, A. Takahashi, S. Amagi, and N. Ooki, Circuit Technology, 6, 71 (1991).

4. K. Koseki, Y. Goto, T. Yamaoka, and T. Tsunoda, Kobunshi Ronbunshu, 24, 331 (1978).

5. M. Koshiba, T. Yamaoka, and T. Tsunoda, Kobunshi Ronbunshu, 37, 227 (1980).

6. K. Koseki, T. Shibata, and T. Yamaoka, Kobunshi Ronbunshu, 44, 173 (1987).

7. A. Nagai, J. Katagiri, A. Takahashi, M. Wajima, and A. Mukoh, Polymer, 31, 2420 (1990).

8. T. G. Fox and J. Loshaek, J. Polym. Sci., 15, 371 (1955).

9. K. C. Rusch, J. Macromol. Sci., B2, 179 (1968).

10. K. C. Rusch and R. H. Beck, Jr., J. Macromol. Sci., B3, 365 (1969).

11. S. Ogata, N. Kinjo, S. Eguchi, and T. Kawata, Kobunshi Ronbunshu, 46, 413 (1989).

12. V. B. Gupta, L. T. Drazal, C. Y.-C. Lee, and M. J. Rich, Polym. Eng. Sci., 25, 812 (1985). 